\title{
La vocación en Ortopedia y Traumatología
}

\author{
Dr. Alfredo F. Guerrini
}

Profesor Consulto de Ortopedia, Universidad Nacional de La Plata, Argentina

El significado de la palabra vocación, en este caso de la Ortopedia y Traumatología (VOT), proviene del latín "vocatio" que significa llamado para una misión útil para el hombre y la sociedad toda.

La condición fue señalada desde la antigüedad, así la Biblia ${ }^{1}$ menciona que hay diversidad de dones otorgados para el bien común, los que serían como un "fuego sagrado", en nuestro caso, la curación. Supone una acción, como servicio o ayuda, con dedicación expresa que hace vivir a la persona de su ejercicio laboral.

La especialidad abarca la ciencia y el arte clínico-quirúrgico del aparato locomotor y el raquis.

Amoli $^{2}$ la ubica a esta como una actividad profesional denominada "workforce" por la cirugía musculoesquelética diferenciándola de partes blandas como la Cirugía Plástica.

La VOT da "sentido a la vida". ${ }^{3}$

Rao y cols. ${ }^{4}$ consideran esta decisión como importante, compleja e individual con componentes inexplicables.

Según Stabile, ${ }^{5}$ la VOT busca identidades sólidas y autónomas, relacionando lo personal con lo institucional, así como un proyecto económico, con un laborioso destino final de acuerdo con Johnson. ${ }^{6}$

El momento cronológico de decisión categórica de una vocación es, muchas veces, dificultoso y en situación vital de transición psicológica con otras exigencias, como la independencia de la vida familiar o personal, la concreción afectiva, etc.

También es partícipe la implicancia demográfica, la ubicación en la realización del ejercicio y la procedencia del ortopedista. ${ }^{3}$

La incertidumbre de la decisión se definirá por la más deseada, ya que se tienen capacidades o intereses para varias opciones. Existen escuelas alemanas que señalan como frecuente el cambio de la VOT en los años mayores, alrededor de los 50, sobre quienes tienen actividad profesional.

En las condiciones salientes precoces del futuro médico ortopedista, está su aptitud e interés con motivación primaria por las ciencias naturales.

Varias cualidades personales convergentes son descritas por Guerado Parra ${ }^{7}$ para la realización futura. Ejemplo, la disposición de asistir a otras personas en forma refleja, con dedicación y continuidad, el razonamiento o saber pensar, discernimiento, modestia, responsabilidad, la inquietud por los conocimientos significativos y la búsqueda de soluciones.

Las aptitudes son las virtudes armónicas llamadas por Hurtado Hoyo "físicas y del alma", guarda la energía moral del recto actuar y una capacidad demostrada en estudios continuados, la que dará la posibilidad de llevar adelante la experiencia documentada, que incorpora saberes y aprendizajes de los enfermos y sus enfermedades donde la teoría facilita la práctica de ahí su motivación.

Cierta destreza manual será necesaria para la cirugía, pero algunos autores la relacionan además de la habilidad, al conocimiento de la zona que a solas condiciones artísticas del cirujano, atribuyéndosele a Fernández: "que no es necesario ser anatomistas para realizar la práctica quirúrgica, pero todos los buenos cirujanos saben anatomía". ${ }^{3}$

La actitud tendrá interés o curiosidad especial en narraciones de patologías o casos observados o valoración de especialistas actuantes en ocasiones médicas, comentarios o informaciones referenciales, al que se adjudica la forma causal de contagio o imitación, a la que $\mathrm{Orgaz}^{9}$ señala el origen más frecuente. Esto se da especialmente en el ámbito familiar.

Dr. ALFREDO F. GUERRINI • alfredo_guerrini@yahoo.com.ar ID

Cómo citar este artículo: Guerrini AF. La vocación en Ortopedia y Traumatología. Rev Asoc Argent Ortop Traumatol 2019;84(3):199-201. http://dx.doi.org/10.15417/issn.1852-7434.2019.84.3.936 
Rowley y cols. ${ }^{10}$ señalan el afecto, el respeto del semejante, la generosidad, la perseverancia, el índice de la responsabilidad, la futura comunicación, como valores morales significativos, que evitarán la negligencia o ignorancia inexcusables en el trato del futuro paciente-hombre en crisis, al que Séneca denominaba "cosa sagrada".

La posibilidad de la formación del espíritu médico de la especialidad señalado por Buzzi ${ }^{11}$ es la "técnica científica, sensibilidad profesional y cultura filosófica" que facilitarán la investigación científica, síntesis de las necesidades del especialista.

Nuestro tema se ha tecnificado significativamente, los tests psicológicos vocacionales son importantes, algunos denominados herramientas por Rascovan. ${ }^{12}$ Estos deben tener un carácter interpretativo y no instructivo, favoreciendo la búsqueda del interesado. Siendo siempre el interés primitivo o intuitivo de singular valor, que se evaluará en una entrevista personal.

La VOT integra inteligencia con voluntad, poniendo ganas a la acción, capacitando en la vida para hacer uso de la libertad con responsabilidad. En su estímulo profesional, reúne eficacia con la satisfacción del ortopedista y del paciente, como en todo, no habrá éxitos sin esfuerzos frente a los progresos permanentes de la Ciencia.

Recordamos la ocurrente definición de la Ortopedia hecha por C. de Anquin, 1973, como una "amante", por placentera y demandante.

La menor incidencia femenina en la especialidad es significativa en todas partes del mundo. En la AAOS, las estadísticas señaladas por Rohde y cols. ${ }^{13}$ arrojan que solo el $4 \%$ de sus miembros son mujeres, cifra que se aproxima a lo que ocurre en nuestro medio. Esta tendencia es mayor en la Ortopedia Infantil, pero igual es baja.

Entre los factores señalados para su deserción figuran la maternidad, el trabajo de guardia, los factores sociales, etc.

El citado autor señala a pesar de que en las residencias es significativamente mayor la proporción de las médicas que se orientan hacia otras especialidades.

La docencia dentro de la función especializada y la publicación de la experiencia, donde se sabe lo que se hace, brinda autoformación que avalan los conocimientos y recibe inquietudes valederas.

La actividad de instituciones afines, como la AAOT con su valioso rol de enseñanza continuada, motiva y mejora nuestra vocación, evitando falencias formativas.

La confianza de la propia vocación le hará llevar adelante los momentos críticos siempre presentes, sin ella no es realizable la práctica cotidiana de táctica y técnica, pero esta exigirá una capacitación específica intensa y permanente.

La vocación cumplida tiene un destino amplio, por lo que se denomina orientación profesional, dentro de la medicina quirúrgica o intervencionista, dentro de la formación recibida y la gratificación alcanzada con esta, según Rao y cols. ${ }^{4}$ o lo que, a su vez, emprende las subespecialidades camino amplio con diversos senderos, con un capítulo previo común que hace al diagnóstico.

Las deficiencias vocacionales existentes en los jóvenes se las atribuye a limitaciones de identidad, patrones deficitarios existentes en la sociedad actual, también existen razones azarosas o imprevistas de origen en la actividad laboral de los especialistas. La presencia de la VOT se encuentra sólo en el 35\% de los casos, lo que condicionaría una forma privilegiada de éxito profesional, una forma de felicidad en su realización, compensando con una obligación mayor de trabajo y reflexión.

Según Liciardo, los profesionales son "dirigentes sociales por naturaleza", aptos para substituir las carencias de la sociedad, de ahí su implicancia esperanzada.

La vocación necesita además del imperativo de la educación continua, la formación específica que promueva el interés y desarrollo personales, un estilo amigable de vida y satisfacción con el proceso formativo, según Grayson y cols. ${ }^{14}$ también requiere una salud psicofísica, para llegar a una buena realización promoviendo el interés y progreso constantes.

La sana competencia profesional (Strelzow y cols..$^{15}$ ) hace competente, en las decisiones diagnóstico-terapéuticas.

Las deserciones precoces muestran un déficit vocacional, aunque las crisis pueden ser producto del cansancio y el estrés.

Las transferencias a otras especialidades son Neurología, Anestesiología, Emergencia, etc., casi poéticamente Güemes definía a nuestra profesión como: "Un arte delicado, una ciencia difícil, un modesto oficio, una noble misión". De ahí su complejidad.

El crudo activismo de la profesión, que no es actividad, según Komar, debe buscar una armonía de equilibrio realizador, que da el cumplimiento ético de no perjudicar al paciente.

La familia debe incluir también el tiempo del profesional en actividad, lo que es vital. 
El hobby comparte la profesionalidad con lo recreativo, guarda un respetuoso lugar dentro de la VOT y este no debe desplazarla. También es una reserva para los años de jubilación, donde se disfruta más a los ortopedistas que a la ortopedia.

El ocaso de esta VOT va llegando cuando la memoria actual es menos explícita, las manos no tan firmes y el interés por la especialidad es menor, con más evocación que hechos, en lo que se propiciara dedicarse a un tema, eligiendo una sola estrella para seguir siendo sembrador, como señalara Yupanqui, y entonces pueden activarse actividades pendientes, como los hobbies.

Es de sabio maestro dejar oportunamente a sus sucesores y confiar el progreso en ellos.

\section{BIBLIOGRAFÍA}

1. ICor 12,4-11.

2. Amoli MA, Flynn JM, Edmonds EW, Glotzbecker MP, Kelly DM, Sawyer JR. Gender differences in pediatric orthopaedics. What are the implications in the future workforce? Clin Orthop Related Res 2016;474(9):1973-8. https://doi.org/10.1007/s11999-016-4984-z

3. Fernández L. XXV Congreso Argentino de Ortopedia y Traumatología, diciembre 1988.

4. Rao RD, Khatib ON, Agarwal A. Factors motivating medical students in selecting a career specialty: relevance for a robust orthopaedic pipeline. J Am Acad Surg 2017;25(7)527-35. https://doi.org/10.5435/JAAOS-D-16-00533

5. Stabile C. Análisis de los factores interactuantes en la problemática vocacional. Revista Española de Cirugía Ortopédica y Traumatología Córdoba, España.

6. Johnson JP, Cassidy DB, Tofte JN, Bariteau JT, Daniels HA. Orthopedic surgery resident debt load and its effect on career choice. Orthopedics 2016;39(3):438-43. https://doi.org/10.3928/01477447-20160315-01

7. Guerado Parra G. Convergencia en la formación especializada de Cirugía Ortopédica. Rev Esp Cir Ortop Traumat 2010;54(5):264. https://doi.org/10.1016/j.recot.2010.06.006

8. Hurtado Hoyo E. El significado de ser Médico. Revista de la Asociación Médica Argentina 2009;122(4):3-5.

9. Orgaz J. Infancia y vocación. Córdoba, Argentina: Editorial Assandri; 1950.

10. Rowley BD, Baldwin DC Jr, Bay RC, Karpman RR. Professionalism and professional values in orthopaedics. Clin Orthop Relat Res 2000;378:90-6. https://doi.org/10.1097/00003086-200009000-00015

11. Buzzi A. El espíritu médico. Revista de la Asociación Médica Argentina 2009;122(2):4-5.

12. Rascovan S. La orientación vocacional como experiencia subjetivante. Buenos Aires: Editorial Pidos SAICF; 2016:161-9.

13. Rohde R, Wolf JM, Adams JE. Where are the women in orthopaedic surgery? Clin Orthop Relat Res 2002;474(9): 1950-6. https://doi.org/10.1007/s11999-016-4827-y

14. Grayson MS, Newton DA, Patrick PA, Smith L. Impact of AOA status and perceived lifestyle on career choices of medical school graduates. J Gen Intern Med 2011;26(12):1434-40. https://doi.org/10.1007/s11606-011-1811-9

15. Strelzow J, Petretta R, Broekhuyse HM. Factor affecting orthopeadics residency selection acruss-sectional surgery. Can J Surg 2017;60(3):186-191. https://doi.org/10.1503/cjs.014915 